\title{
PEMBANGUNAN DAN KESAHAN MODUL PERGERAKAN KREATIF DALAM ELEMEN DRAMA (PETIF-MA) BAGI KANAK-KANAK PRASEKOLAH
}

Development And Validity Of Creative Movement Module In Drama Element (PETIF-MA) For Preschool Students

Jamariah Muhamad ${ }^{1}$, Loy Chee Luen ${ }^{2}$

Fakulti Pembangunan Manusia, Universiti Pendidikan Sultan Idris, 35900 Tanjong Malim, Perak

fityhaq73@gmail.com ${ }^{1}$,Loy.C.L@fpm.upsi.edu.my²

\begin{abstract}
ABSTRAK
Tujuan kajian ini adalah untuk membangunkan modul pengajaran dan pembelajaran pergerakan kreatif dengan unsur drama (PeTif-Ma) bagi kanak-kanak prasekolah. Modul PeTif-Ma ini menekankan kepada kemahiran pergerakan kreatif bersama dengan unsur drama bagi membantu kepada peningkatan interaksi lisan kanak-kanak prasekolah yang berumur lima dan enam tahun. Modul PeTif-Ma ini berdasarkan reka bentuk pengajaran model ASSURE. Model ASSURE mempunyai enam langkah yang perlu diikuti secara sistematik bagi menghasilkan modul yang mantap dan menepati objektif yang hendak dicapai. Kajian ini berbentuk kuantitatif yang menggunakan kaedah tinjauan bagi mendapatkan pandangan pakar melalui soal selidik berkaitan dengan kandungan Modul PeTif-Ma. Sampel kajian terdiri daripada lima orang pakar. Dapatan kajian menunjukkan Modul PeTif-Ma ini mempunyai kesahan kandungan yang tinggi. Justeru itu, Modul PeTif-Ma ini diharapkan dapat memberi pendedahan dan membantu guru prasekolah terhadap pengajaran dan pembelajaran dalam bilik darjah serta membantu kepada perkembangan kanak-kanak prasekolah.
\end{abstract}

kata Kunci : pergerakan kreatif, elemen drama, kesahan kandungan, assure, kanak-kanak prasekolah

\section{ABSTRACT}

The purpose of this study is to develop the teaching and learning modules of creative movements with drama elements (PeTif-Ma) for preschoolers. This PeTif-Ma module emphasizes on creative movement skills along with drama elements to help increase the oral interaction of preschool children aged five and six years. This PeTif-Ma module is based on the ASSURE model teaching design. The ASSURE model has six steps to systematically follow to produce a robust module and meet the objectives to achieve. This study was quantitative using a survey method to get an expert opinion through a 
questionnaire related to the content of PeTif-Ma Module. The research sample consists of five experts. The findings show that this PeTif-Ma Module has a high content validity. Hence, the PeTif-Ma Module is expected to provide exposure and help preschool teachers towards teaching and learning in the classroom as well as assisting the development of preschool children.

Keyword: Creative movement, drama element, preschool children, ASSURE, content validity

\section{PENGENALAN}

Umum mengetahui kanak-kanak secara normalnya suka bergerak. Ini kerana pergerakan merupakan sebahagian daripada kehidupan mereka dari saat mereka dilahirkan. Melalui pergerakan perluahan rasa dan emosi kanak-kanak tercetus secara tidak langsung. Melalui pergerakan juga kanak- kanak merasa gembira dan bahagia di samping memberi peluang kepada perkembangan psikomotor mereka. Peluang untuk bergerak harus diberikan kepada kanak-kanak atas banyak sebab. Menurut Andress (1991) pembelajaran utama kanak-kanak ialah melalui pergerakan. Maka aktiviti pergerakan kreatif yang menggabungkan aktiviti pergerakan, kreatif, aktif dan menyeronokkan menjadi satu cara untuk mencapai matlamat dan hasrat KSPK (2017) dan harus diberi penekanan dalam aspek pengajaran dan pembelajaran di prasekolah agar manfaat dalam aktiviti pergerakan kreatif membantu perkembangan kanakkanak secara holistik.

Namun modul pengajaran dan pembelajaran dalam bidang Pergerakan Kreatif kanakkanak prasekolah adalah terhad di Malaysia amnya dan di prasekolah khususnya. Sememangnya terdapat beberapa modul telah disediakan oleh Kementerian Pendidikan melalui Bahagian Pendidikan Guru bagi panduan kepada guru prasekolah seperti Modul Bersepadu dan Modul Bertema dan Modul Teras namun masih kekurangan Modul khusus bagi pergerakan kreatif atau tunjang kreativiti dan estetika. Ling (2014) telah membina satu modul aktiviti seni kreatif namun hanya tertumpu kepada bidang seni visual sahaja. Sehingga kini, masih terdapat kekurangan modul pengajaran dan pembelajaran seni kreatif menjurus khusus kepada pergerakan kreatif kanak-kanak. Rentetan daripada kekurangan itu, pembinaan Modul Pergerakan Kreatif Berunsur Drama (PeTif-Ma) ini dapat mengatasi masalah kekurangan bahan atau modul dalam pengajaran pergerakan kreatif kanak-kanak prasekolah.

\section{KEPERLUAN PERGERAKAN KREATIF KEPADA KANAK-KANAK}

Pergerakan kreatif ditakrifkan sebagai tidak kompetitif, spontan yang berpandu, pergerakan badan yang membolehkan kanak-kanak untuk meluahkan emosi, bercerita, dan membina hubungan (Greer-Paglia, 2006). Sementara itu, menurut Salmah (1994) pula definisi pergerakan kreatif adalah penjelajahan pergerakan, pendidikan pergerakan moden, pendidikan pergerakan, pergerakan pendidikan berirama dan drama kreatif. Selain dua definisi itu, pergerakan kreatif juga merupakan seni tarian yang menggunakan pergerakan semula jadi 
tubuh badan (Kaufmann \& Ellis, 2007) dan ekspresi secara kreatif (Bannon, 1994; Cheung, 2010; Dow, 2010; Oshuns, 1977). Untuk itu, melalui pergerakan kreatif, kanak-kanak bebas untuk mengekspresi perasaan dan personaliti mereka mengikut kehendak dan style mereka. Mereka tidak memerlukan sebarang contoh atau meniru orang lain. Ini kerana dalam pergerakan kreatif penekanan lebih diberikan kepada proses yang berlaku dalam pergerakan kreatif bukan kepada hasil pergerakan kreatif itu sendiri.

Pergerakan kreatif boleh memberi kesan yang kuat dalam kehidupan seharian kanak-kanak kerana aktiviti pergerakan kreatif ini melibatkan aktiviti fizikal dan sebagai salah satu cara mereka mengekpresi diri mereka. Bagi kanak-kanak pergerakan kreatif ini menawarkan pengalaman yang kaya dengan kemahiran meneroka dan mencipta, dengan dengan cara yang menyeronokkan dan mengembirakan. Pergerakan kreatif juga boleh menjadi medan kepada kanak-kanak meluahkan perasaan mereka mengenai sebarang keadaan dalam kehidupan mereka (Chueng, 2010), atau respons kepada cerita, lagu atau sajak (Dow, 2010) yang mereka dengari. Hal ini kerana asas pergerakan kreatif boleh berlaku dalam apa jua situasi yang membolehkan kanak-kanak berasa bebas untuk mengerakkan tubuh badannya di samping meluahkan perasaan mereka sama ada melalui lagu, puisi, irama atau dalam keadaan senyap sekali pun (Mayesky, 2015). Pelahiran emosi dan perasaan dengan cara yang betul dan selamat amat penting kepada kanak-kanak. Kanak- kanak yang tidak mampu melahirkan perasaan atau memendam rasa akan memberi kesan negatif bukan hanya kepada perkembangan emosi mereka malah kepada sahsiah dan jati diri mereka.

Zakkai (1997) pula menyatakan bahawa pelajar akan yang terlibat dalam aktiviti pergerakan bukan sahaja mendominasikan kecerdasan kinestetik tetapi dapat memahami konsep dan tema dengan lebih baik dan dapat meningkatkan kemahiran berfikir. Selain dari itu, aktiviti pergerakan juga merupakan satu kemahiran komunikasi yang unik, dapat membangunkan kecerdasan ruang dan secara tidak langsung dapat membentuk persekitaran yang sihat antara satu sama lain dengan wujudnya kerjasama. Dapatan-dapatan daripada kajian ini menunjukkan bahawa pergerakan kreatif bukan hanya tertumpu pada pergerakan fizikal sahaja namun mampu memberi kesan yang positif kepada perkembangan kognitif dan afektif. Ini bersesuaian dengan cabaran kehidupan masa kini yang semakin mencabar dan memerlukan kekuatan dalaman dan luaran.

\section{ELEMEN PERGERAKAN KREATIF}

Pergerakan kreatif mempunyai tema atau beberapa unsur asas yang menjadi landasan kepada pergerakan tersebut. Menurut Laban (1975) terdapat 16 tema dalam pergerakan kreatif ini. Tema ini telah dibahagikan pula kepada dua tahap iaitu tahap pergerakan asas dan tahap lanjutan. Dalam kajian ini penumpuan hanya diberikan kepada tahap pergerakan asas kerana sesuai dengan peringkat umur kanak-kanak prasekolah yang belum menguasai sepenuhnya pergerakan asas mahupun pergerakan kreatif ini. Tahap pergerakan asas ini yang membolehkan kanak-kanak bergerak dengan kesedaran empat unsur yang telah diperkenalkan. Empat unsur ini juga telah diguna pakai dalam kemahiran pergerakan kreatif kerana pergerakan merupakan asas kepada pergerakan kreatif. Melalui elemen ini dapat membantu kanak-kanak memperhalusi pergerakan kreatif mereka melalui pergerakan. 
Rajah 1 menunjukkan empat unsur tersebut:

\begin{tabular}{ll}
\hline Unsur asas & Kriteria \\
\hline Tubuh badan & $\begin{array}{l}\text { Apakah yang dilakukan oleh tubuh badan atau bahagian-bahagian } \\
\text { tubuh badan } \\
\text { Ruang }\end{array}$ \\
Di mana dan bagaimana ruang digunakan dalam aktiviti pergerakan \\
Kubungan & $\begin{array}{l}\text { Kagaiti pergerakan } \\
\text { lain dan objek }\end{array}$ \\
\hline
\end{tabular}

Rajah 1: Elemen Pergerakan Kreatif Laban (1975)

Berdasarkan rajah 1, pergerakan kreatif kanak-kanak mempunyai empat elemen asas iaitu tubuh badan, ruang, masa dan perkaitan (Laban, 1975). Elemen ini memberi penekanan perkembangan motor kasar kanak-kanak dan kreativiti tingkah laku serta pemikiran bagi pelahiran kanak-kanak secara sihat. Aktiviti pergerakan kreatif seperti menari, bergerak dan muzik adalah perkara semula jadi dalam pembelajaran kanak-kanak secara kreatif (Rebecca, 2011).

Maka, pembelajaran pergerakan kreatif sememangnya berada dalam landasan pembelajaran kanak-kanak kerana selain dari membantu perkembangan kanak-kanak secara holistik, pergerakan kreatif ini juga selari dengan perkembangan semula jadi dan naluri kanakkanak prasekolah. Namun jika diamati senario sekarang, pergerakan kreatif yang merupakan satu elemen pengajaran kurang diberi penumpuan oleh guru prasekolah kerana penekanan terhadap kesediaan kanak-kanak lebih tertumpu pada pencapaian kognitif sahaja (Haslina, 2013). Keadaan ini dibimbangi akan berterusan dan memberi impak yang kurang baik terhadap perkembangan dan pertumbuhan kanak-kanak secara konsisten dan menyeluruh.

\section{MODEL PEMBINAAN MODUL PeTif-Ma}

Pembinaan Modul PeTif-Ma ini berdasarkan kepada reka bentuk pengajaran model ASSURE (1996). Terdapat enam langkah dalam fasa pembinaan modul mengikut model pembinaan ASSURE ini iaitu A = Analisis Murid (Analyse Learner), $\mathrm{S}=$ Nyatakan Objektif (State Objective) ,S = Pilih Kaedah, Media dan bahan (Select method, media and material) , U = Guna Media dan Bahan (Use Media and Material) dan $\mathrm{R}=$ Perlukan Penglibatan Murid (Require learner) serta $\mathrm{E}=$ Menilai dan Menyemak Semula (Evaluation).

Berdasarkan kepada enam langkah ASSURE (1996) ini, pengkaji telah membahagikan kepada 3 fasa iaitu fasa pembinaan, fasa pelaksanaan dan fasa penilaian (Nor Miza, 2015). Pembahagian kepada 3 fasa ini dibuat bagi memudahkan aliran carta proses kerja dalam pembinaan modul. Ini kerana langkah-langkah dalam ASSURE adalah sangat penting untuk diikuti secara turutan dan sistematik bagi menghasilkan modul yang benar-benar memberi 
makna dan mencapai objektif. Model ASSURE (1996) ini telah digunakan sebagai panduan dalam proses pembinaan sesuatu modul seperti yang telah dilaksanakan oleh Nor Miza (2015) dan Zamri \& Nur Aisyah (2011).

Modul PeTIf-Ma ini dibangunkan bagi memberi panduan pengajaran kepada guruguru prasekolah tentang pengajaran pergerakan kreatif kanak-kanak prasekolah secara lebih mudah, tepat dan berkesan. Selain itu, modul Petif-Ma ini menjadikan Semakan Kurikulum Standard Prasekolah Kebangsaan (2017) sebagai panduan dalam merangka sebarang aktiviti dalam modul agar aktiviti yang terdapat dalam modul ini mengikut acuan dan matlamat pendidikan prasekolah Kebangsaan. Modul ini juga dibina bagi membantu kanak-kanak berinteraksi secara lisan melalui pergerakan kreatif berbantukan elemen drama. Rajah di bawah ialah carta aliran dalam 3 fasa mengikut langkah-langkah dalam pembinaan modul mengikut model ASSURE.

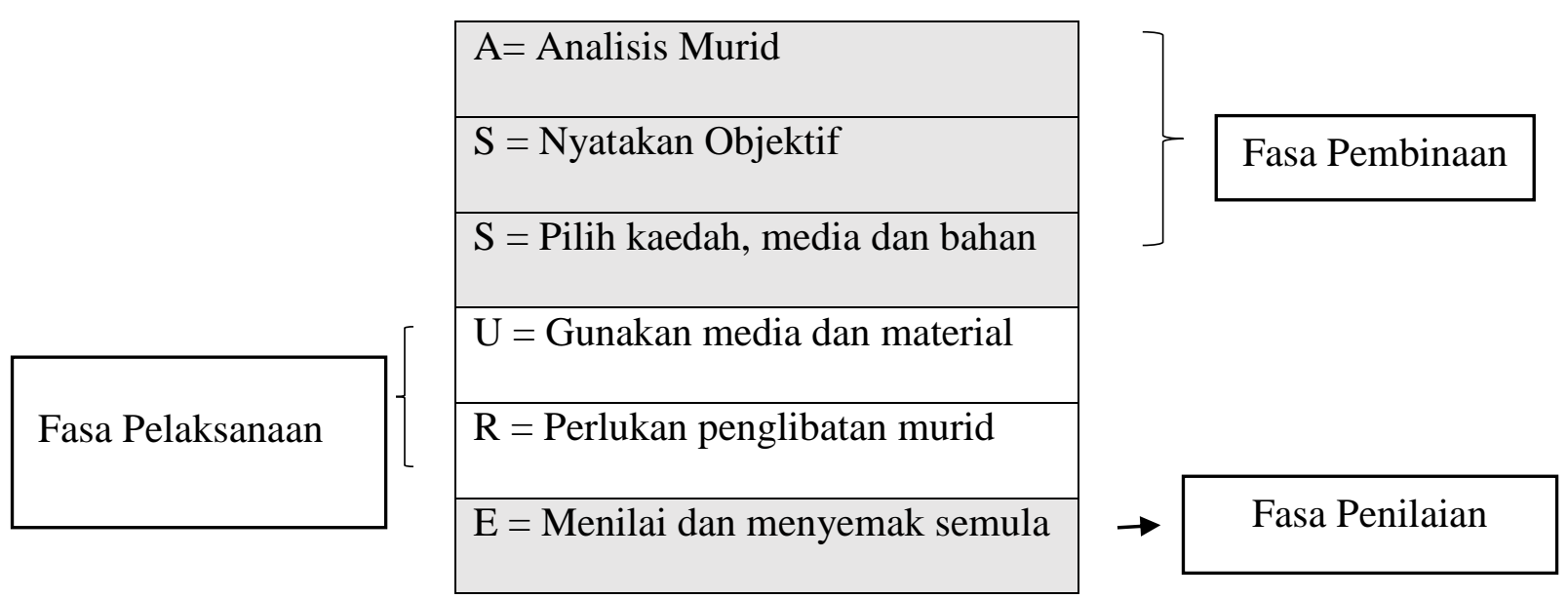

Rajah 2: Ubah suai carta aliran pembinaan modul berdasarkan Model ASSURE (1996)

Berdasarkan rajah pembinaan modul ini dibahagikan kepada tiga fasa iaitu fasa pembangunan, fasa pelaksanaan dan fasa penilaian. Fasa pembangunan melibatkan langkah analisis murid, menyatakan objektif dan pemilihan kaedah, media dan bahan. Dalam fasa pembangunan, langkah-langkah tersebut perlu dijalankan dan dianalisis dengan teliti agar modul yang dibangunkan menepati sasaran dan objektif yang hendak dicapai. Sementara itu, pada fasa pelaksanaan pula melibatkan langkah menggunakan media dan material serta memerlukan penglibatan murid. Dalam masa pelaksanaan, pengkaji perlu membuat penelitian yang lebih rapi agar jika terdapat beberapa kekurangan, modul ini boleh diperbaiki. Pada fasa akhir iaitu fasa penilaian pula melibatkan langkah menilai dan menyemak semula modul yang dibina. Semasa fasa ini, modul tersebut akan diubahsuai mengikut kepada kekurangan dan masalah ketika fasa pelaksanaan. Turutan langkah pembinaan modul perlu diikut mengikut spesifikasi yang ditetapkan agar dapat menghasilkan modul yang bermutu dan menepati objektif. Berikut ialah langkah-langkah yang terdapat dalam reka bentuk model ASSURE. 


\section{Fasa Pembangunan}

\section{Analisis Murid}

Langkah pertama ini, pengkaji mengenal pasti ciri-ciri umum kanak-kanak seperti nisbah jantina, jumlah murid prasekolah, umur, persekitaran dan latar belakang kanak-kanak prasekolah. Dalam kajian ini, pengkaji mengambil kira tahap keupayaan kanak-kanak dari sudut perkembangan psikomotor dan aspek interaksi lisan mereka berdasarkan kepada buku perkembangan profil individu kanak-kanak dan cadangan daripada gutu. Ini kerana menurut Lohr (1998) dalam menganalisis murid akan melibatkan proses siasatan kepada murid, kandungan dan tugasan manakala Shambaugh dan Magliaro (2006) menyatakan bahawa proses ini mengambil kira aspek murid, kandungan dan konteks pengajaran.

\section{Menyatakan Objektif Pembelajaran}

Dalam hal ini, pengkaji akan terlebih dahulu menentukan hasil pembelajaran yang akan dicapai daripada modul PeTif-Ma ini. Daripada hasil pembelajaran mengikut tunjang yang terdapat dalam semakan KSPK (2017) ini objektif modul akan dapat ditentukan. Penentuan dan penetapan objektif ini sangat penting kerana modul yang dibina ini akan mengikut acuan dan tekal dalam KSPK (2017).

\section{Pemilihan Kaedah, Media dan Bahan}

Pemilihan kaedah, media dan bahan dilakukan setelah mengenal pasti objektif pembelajaran atau standard pembelajaran yang hendak dicapai. Dalam kajian ini, pengkaji memilih kaedah berpusatkan kepada murid dan guru hanya sebagai fasilitator dan pembelajaran secara aktif. Sementara itu, bahan dan media yang digunakan bersesuaian dengan usia kanak-kanak prasekolah yang berumur lima dan enam tahun.

\section{Fasa Pelaksanaan}

\section{Gunakan media dan material}

Sementara itu dalam langkah ini, pengkaji perlu memastikan agar penggunaan bahan dan media yang telah dipilih perlu menyediakan pengalaman pembelajaran yang bermakna kepaa kanak-kanak. Dalam hal ini, pengkaji perlu memastikan agar Modul PeTif-Ma ini menyediakan aktiviti yang bukan sahaja membantu guru menjalankan pengajaran dengan baik, mudah dan berkesan namun memastikan juga berlaku perkembangan interaksi lisan dan pergerakan kreatif kanak-kanak prasekolah.

\section{Perlukan penglibatan murid}

Bagi memastikan bahawa modul yang dibina itu berkesan, pengkaji perlu memastikan aktiviti-aktiviti disusun sesuai dengan perkembangan kanak-kanak dan melibatkan penglibatan yang aktif oleh kanak-kanak prasekolah sebagai peserta kajian. Tambahan pula modul PeTif-Ma ini sememangnya memerlukan pergerakan dan interaksi yang aktif 
daripada kanak-kanak prasekolah. Ini Secara tidak langsung akan membantu perkembangan domain yang lain seperti domain kognitif dan efektif.

\section{Fasa Penilaian}

\section{Menilai dan menyemak semula}

Modul PeTif-Ma akan disemak dan dinilai setelah dilakukan oleh pengkaji pada langkah terakhir ini. Setelah PdP dijalankan, pengkaji dan guru selaku individu yang menjalankan modul tersebut membuat penilaian terhadap keberkesanan bahan, media dan kaedah yang digunakan secara menyeluruh. Beberapa persoalan perlu dibincangkan dalam langkah ini. Dalam kajian ini, beberapa persoalan perlu dibincangkan oleh pengkaji sebagaimana yang dilakukan oleh Noor Miza Abdul Rahman (2015) dalam kajiannya. Antara persoalannya ialah:

- Adakah objektif-objektif dalam modul tersebut tercapai?

- Adakah aktiviti yang dijalankan menggalakkan kemahiran interaksi, lisan kanakkanak?

- Adakah alat dan bahan media yang digunakan membantu proses PdP dan sesuai dengan aktiviti?

- Adakah suasana pembelajaran sesuai dan selesa?

- Adakah ruang yang disediakan sesuai?

- Adakah terdapat keperluan penambahbaikan?

- Adakah berlaku peneguhan kepada kanak-kanak prasekolah?

- Adakah aktiviti pergerakan kreatif berlaku dengan baik dalam PdP?

Dalam langkah ini semakan pakar bagi kesahan kandungan sangat perlu bagi memastikan modul yang dibina bertepatan dengan objektif kajian dan objektif modul yang dibina. Selain itu, rujukan terhadap KSPK (2017) juga dibuat bagi memastikan segala aktiviti yang terdapat dalam modul ini selaras dan selari dengan keperluan dan kehendak pendidikan prasekolah di samping mengikut keperluan dan perkembangan kanak-kanak.

\section{METODOLOGI KAJIAN}

Kajian ini berbentuk kuantitatif yang menggunakan kaedah tinjauan untuk mengenal pasti kesahan kandungan Modul PeTif-Ma. Pembangunan modul perlu melalui proses pembinaan draf bagi memastikan modul yang dibina menepati sasaran dan objektif yang telah ditetapkan. Dapatan dari analisis keperluan, tinjauan literatur dan semakan kurikulum diperlukan semasa proses pembinaan draf modul ini. Selain itu, modul yang dibangunkan, perlu disemak oleh pakar bidang bagi mendapatkan kesahan kandungan modul Dalam kajian ini, pengkaji menjalankan kesahan kandungan Modul Pergerakan Kreatif Kanak-kanak Melalui Unsur Drama (PeTif- Ma) bagi memastikan kandungan Modul PeTif- Ma yang dibina tepat dan diakui berkualiti.

Penggunaan kesahan dalam kajian ialah untuk menguji sejauh mana ketepatan sesuatu alat ukur yang dikaji dalam sesuatu kajian. Menurut Pallant (2007), kesahan adalah merujuk 
kepada sejauh mana sesuatu alat kajian yang digunakan untuk mengukur dengan tepat ciri-ciri yang dikaji dalam sesebuah kajian. Ini memberi makna bahawa sesuatu instrumen itu dianggap sah dan boleh diguna pakai jika dapat mengukur apa yang sepatutnya diukur dan sesuatu alat atau instrumen pengukuran adalah juga sah apabila pembinaan alat itu memenuhi atau menepati fungsi dan objektif pembinaannya. Menurut Sidek \& Jamaluddin (2012), modul juga dianggap sebagai satu alat pengukuran kerana modul itu sendiri merupakan alat, bahan dan sumber yang dijadikan panduan bagi pengkaji mendapatkan maklumat berkaitan dengan kajian yang dijalankan. Begitu juga menurut Md Noor, Nurul Ain dan Norazani (2016) menyatakan bahawa kesahan modul merujuk pada ketepatan konsep dan kandungan sesuatu modul.

Sementara itu, menurut Othman (2014), proses kesahan merupakan indikator bagi ketepatan kajian iaitu sama ada kajian tersebut memberi gambaran yang benar tentang fenomena yang dikaji atau tidak. Proses kesahan ini juga perlu dilakukan oleh individuindividu yang pakar dalam bidang yang berkaitan dengan isi kandungan modul. Ini bertepatan dengan pernyataan Noraini (2013), yang menyatakan bahawa bagi meningkatkan kesahan kandungan sesuatu modul, pengkaji perlu mendapatkan pandangan dan maklum balas daripada pakar untuk menilai dan memastikan elemen-elemen yang terkandung dalam sesuatu modul mewakili bidang kajian yang hendak dikaji. Ini kerana maklum balas dan pandangan daripada pakar-pakar ini sangat penting bagi mendapatkan modul yang bermutu dan boleh diguna pakai.

Bagi kesahan kandungan modul pula menurut Anastasi \& Urbina (1997), kesahan kandungan adalah suatu penilaian sistematik terhadap kualiti kandungan sesuatu modul yang mengukur perkara yang sepatutnya diukur. Di tambah pula, bagi memastikan modul yang dibina itu mantap dan boleh diguna pakai, peratus kesahan kandungan modul perlu diambil kira. Ini kerana kesahan yang tinggi menunjukkan dapatan yang diperoleh adalah berdasarkan fakta dan mampu memberi justifikasi yang tepat (Noraini, 2013).

Pengkaji telah menyediakan satu salinan lengkap modul PeTif-Ma yang mengandungi pengenalan, objektif umum dan objektif khusus modul, asas teori yang digunakan, kandungan keseluruhan dan lampiran bahan bantu mengajar. Modul yang disediakan untuk diteliti dan dinilai serta diberi cadangan oleh panel pakar. Pemilihan kumpulan pakar dalam kajian ini berdasarkan kepada kepakaran, pengalaman dan kesesuaian dengan isi kandungan modul yang dibangunkan. Dalam kajian ini, kriteria pemilihan pakar adalah berdasarkan kepada (i) kepakaran dan pengetahuan dalam bidang awal kanak-kanak. (ii) kepakaran dan pengalaman dalam bidang pergerakan kreatif dan drama (iii) kepakaran dan pengalaman dalam bahasa dan (iv) pengamal atau guru yang berpengalaman dalam pendidikan awal kanak-kanak. Pengamal atau guru yang berpengalaman dalam bidang pendidikan awal kanak-kanak pula diperincikan lagi dengan memastikan mereka memahami dan melaksanakan pengajaran dan pembelajaran berdasarkan KSPK (2017). Senarai panel pakar adalah seperti jadual di bawah. 
Jadual 1: Profil Panel Pakar

\begin{tabular}{lll}
\hline Bil & Kelayakan & Kepakaran \\
\hline 1. & Dr (Pensyarah IPG) & Pendidikan Awal Kanak-kanak \\
2. & Profesor (Pensyarah Kanan & Pembinaan Modul \\
& Universiti) & \\
3. & Dr (Pensyarah Universiti) & Pergerakan kreatif dan Drama \\
4. & Juru latih Utama & Pendidikan Awal Kanak-kanak \\
5. & Ketua Bidang & Bahasa \\
\hline
\end{tabular}

Penilaian kesahan kandungan modul dibuat menggunakan soal selidik kesahan isi kandungan modul yang memerlukan penilai memberikan jawapan berbentuk skala likert lima mata iaitu : (1) sangat tidak setuju, (2) tidak setuju, (3) tidak pasti, (4), setuju dan (5) tidak setuju. Data dianalisis menggunakan kaedah pengiraan kesahan kandungan modul yang dicadangkan oleh Tuckman dan Waheed (1981). Tuckman dan Waheed (1981) dalam Sidek dan Jamaludin (2012) menyatakan penilaian pakar yang melebihi nilai pekali $70 \%$ mempunyai kesahan kandungan yang baik dan telah menguasai tahap pencapaian yang tinggi. Modul yang mempunyai kesahan kandungan yang tinggi akan menghasilkan pencapaian mengikut objektif yang ingin diukur oleh pengkaji (Md Noor et al., 2016). Rumus bagi penilaian skor adalah seperti berikut :

\section{$\underline{\text { Jumlah Skor Pakar }}$ X $100 \%=$ Pencapaian Kesahan Kandungan}

Skor maksimum

Satu set soal selidik kesahan kandungan modul yang diubahsuai daripada Russell (1974) telah dibina untuk mendapatkan kesahan kandungan secara keseluruhan bagi Modul PeTifMa. Menurut Russel (1974), item kesahan kandungan modul mempunyai lima perkara, iaitu; (i) menepati sasaran populasi; (ii) kaedah pelaksanaan modul adalah bersesuaian; (iii) masa yang diperuntukkan untuk menjalankan modul adalah mencukupi; (iv) modul berjaya meningkatkan pencapaian pelajar dalam aspek yang disasarkan; dan (v) modul berjaya mengubah sikap pelajar ke arah yang lebih cemerlang.

\section{DAPATAN KAJIAN}

Dapatan kajian kesahan modul terdiri daripada kesahan kandungan secara keseluruhan bagi Modul PeTif-Ma berdasarkan ubah suai dari soal selidik kesahan kandungan modul Russell (1974). Hasil daripada penilaian pakar seramai lima orang, nilai kesahan kandungan bagi Modul Petif-Ma dapat dilihat dalam Jadual 1 berikut: 
Jadual 2: Kesahan Kandungan secara keseluruhan mengikut item bagi Modul PeTif-Ma

\begin{tabular}{lcc}
\hline \multicolumn{1}{c}{ Item } & $\begin{array}{c}\text { Modul PeTif-Ma } \\
(\%)\end{array}$ & $\begin{array}{c}\text { Pandangan } \\
\text { Pakar }\end{array}$ \\
\hline $\begin{array}{l}\text { Kandungan modul PeTif-Ma ini } \\
\text { menepati sasaran populasi. }\end{array}$ & 96 & Diterima \\
$\begin{array}{l}\text { Kandungan modul PeTif-Ma ini boleh } \\
\text { dilaksanakan dengan sempurna. }\end{array}$ & 76 & Diterima \\
$\begin{array}{l}\text { Kandungan modul PeTif-Ma ini } \\
\text { bersesuaian dengan masa yang } \\
\text { diperuntukkan. }\end{array}$ & 76 & Diterima \\
$\begin{array}{l}\text { Kandungan modul PeTif-Ma ini } \\
\text { meningkatkan prestasi kanak-kanak. }\end{array}$ & 88 & Diterima \\
$\begin{array}{l}\text { Kandungan modul PeTif-Ma ini boleh } \\
\text { mengubah sikap kanak-kanak ke arah } \\
\text { yang lebih cemerlang. }\end{array}$ & 88 & Diterima \\
\hline
\end{tabular}

Berdasarkan Jadual 2 menunjukkan peratus keseluruhan bagi setiap item dalam soal selidik kesahan kandungan melebihi daripada $70 \%$. Pengkaji mendapati peratus yang paling rendah ialah 76 peratus bagi item dua iaitu kandungan modul PeTif-Ma ini boleh dilaksanakan dengan sempurna. Sementara peratus kesahan kandungan yang paling tinggi ialah 96 peratus iaitu bagi item pertama iaitu kandungan Ini menunjukkan bahawa kesahan kandungan modul PeTif-Ma adalah mencapai tahap pencapaian pencapaian yang tinggi dan boleh diguna pakai.

\section{KESIMPULAN}

Kajian ini juga membuktikan bahawa modul PdP pergerakan kreatif berasaskan elemen drama untuk kanak-kanak (PeTif-Ma) boleh dibangunkan secara empirikal melalui prosedur pembangunan modul yang sistematik dengan menggunakan reka bentuk pembangunan Model ASSURE. Berdasarkan dapatan kesahan modul melalui kesahan kandungan oleh pakar dan penilai terhadap modul PeTif-Ma ini mendapati bahawa kandungan modul ini merangkumi kandungan modul yang sewajarnya, sesuai dengan sasaran populasi, menepati objektif yang telah ditetapkan di samping bersesuaian dengan masa yang diperuntukkan. Ini bertepatan dengan Russel (1974) yang menyatakan bahawa modul yang baik dan bermutu perlu melepasi lima perkara iaitu i) menepati sasaran populasi, ii) modul dapat dilaksanakan dengan sempurna iii) bersesuaian dengan peruntukan masa, iv) peningkatan pencapaian terhadap aspek yang hendak dicapai dan iv) boleh mengubah sikap yang lebih baik. Kesahan kandungan ini juga telah dilakukan oleh pengkaji lain terhadap modul mereka antaranya Aliza (2016), Aziz (2010) dan Jazimin (2011).

Pengkaji berjaya membina Modul PeTif-Ma yang spesifik dan lengkap untuk kanakkanak prasekolah. Dapatan kesahan kandungan Modul PeTif-Ma menunjukkan kandungan Modul PeTif-Ma adalah sah dan berkualiti dan boleh diguna pakai oleh guru 
prasekolah. Justeru itu, pengkaji berharap agar Modul PeTif-Ma ini dapat disebarluas dan diguna pakai bagi membantu pengajaran guru prasekolah dalam PdP terutama dalam pengajaran pergerakan kreatif dan interaksi lisan kanak-kanak prasekolah.

\section{RUJUKAN}

Ahmad Jazimin, J, Abdul Malek, A.R, Mohammad Nasir, B \& Mohammad Aziz, S. (2011). Modul Kaunseling Kelompok CTRT: Pendekatan Menangani Permasalahan Disiplin Pelajar. Tanjong Malim: Penerbit Universiti Pendidikan Sultan Idris.

Anastasia, A. \& Urbina, S. (1997). Psychological testing. Upper Saddle River: Prentice- Hall.

Andress, B., Ed. (1992). Promoting Practices: Prekindergarten Music Education. Reston.

Bannon, V. (1994). Dance/Movement Therapy with Emotionally Disturbed Adolescents. Paper presented at the "Safe Schools, Safe Students: A Collaborative Approach to Achieving Safe, Disciplined and Drug-Free Schools Conducive to Learning" Conference, Washington, DC. Brother Publisher.

Cheung, R. H. P. (2010). Designing movement activities to develop children's creativity in early childhood education. Early Child Development and Care, 180, 377-385. http://dx.doi.org/10.1080 103004430801931196

Dow, C. B. (2010). Young Children and Movement: The Power of Creative Dance. Young Children, 30-35. Early Childhood Education. Early Child Development and Care, 180(3), 377-385 Educational Psychology, Vol 85(4), Dec 1993, 571-581.

Greer-Paglia, K. (2006). Examining the Effects of Creative Dance on Social Competence in Children with Autism: A Hierarchal Linear Growth Modelling Approach (Doctoral Dissertation).

Haslina, H. (2013). Pembinaan Instrumen Kesediaan Belajar Awal Kanak-Kanak (Ikbak). Universiti Sains Malaysia.

Kaufmann, K. \& Ellis, B. (2007). Preparing Pre-Service Generalist Teachersto Use Creative Movement in K-6. Journal of Dance Education, 7(1), 7-13.

Kementerian Pelajaran Malaysia. (2016). Kurikulum Standard Prasekolah Kebangsaan: Dokumen standard kurikulum dan pentaksiran. Kuala Lumpur: Bahagian Pembangunan Kurikulum.

Laban. R. (1975). The Mastery of Movement. Boston: Plays, Inc. Longsdon. B. and Barret. K. Physical Education for Children.

Ling, P.K. (2010). Pelaksanaan Aktiviti Seni Kreatif dalam Pendidikan Prasekolah Malaysia. EDUCATIONIST. Vol. IV No 1 Januari.

Lohr, L. (1998). Using ADDIE to design a Web-Based Training Interface. In Society for Information Technology and Teacher Education International Conference (pp. 440-443).

Mayesky, M. (2015). Creative Activities and Curriculum for Young Children (11td Ed.). Cengage Learning Stamford CT: USA.

Md Noor, S. , Nurul Ain, M.D., \& Norazani, A. (2016). Kesahan dan kebolehpercayaan Modul I-Sc (Islamic Spiritual Counseling) ke atas pelajar bermasalah tingkah laku. International Journal of Islamic Thought, Vol. 9, 32-43.

Nor Miza, A.R. (2015). Pembinaan Modul Berasaskan Pendekatan Projek Untuk Meningkatkan Kemahiran Berkomunikasi Murid Tadika. (Doctoral Dissertation).

Noraini, I. (2013). Penyelidikan dalam pendidikan (edisi kedua). Kuala Lumpur: McGraw Hill Education (Malaysia) Sdn. Bhd.

Oshuns, M. G. (1977). An Exploratory Study of Creative Movement asa Means of Increasing Positive Self-Concept, Personal, and Social Adjustment of Selected 7thGrade Students (Doctoral Dissertation).

Othman, L. (2014). Penyelidikan kualitatif: Pengenalan kepada teori dan metode. Tanjong Malim, Perak: Penerbit Universiti Pendidikan Sultan Idris.

Rebecca R.B . (2011). Movement, Art, and Child Development Through the Lens of an Innovative Use of the Kestenberg Movement Profile. American Journal of Dance Therapy 
Rusell, J. D. (1974). Modular instruction: A guide to the design, selection, utilization and evaluation of modular materials. United States: Publishing Company.

Salmah, A. (1994). Pergerakan kreatif dan pendidikan. Flo Enterprise Sdn. Bhd. Petaling Jaya.

Shambaugh, N., \& Magliaro, S. G. (2006). Instructional Design: A Systematic Approach for Reflective Practice. United States of America: Pearson Education Inc.

Sidek, M.N, \& Jamaludin, A. (2005). Pembinaan Modul: Bagaimana Membina Modul Latihan dan Modul Akademik. Serdang: Penerbit Universiti Putra Malaysia.

Tuckman, B. W., \& Waheed, M. A. (1981). Evaluating an individualized science programmed for community college student. Journal of Research in Science Teaching, 18, 489-495.

Zakkai, J. D. (1997). Dance as a way of knowing.. Portland, ME: Stenhouse.

Zamri Mahamod \& Nur Aisyah Mohamad Noor. (2011). Persepsi guru tentang penggunaan aplikasi multimedia dalam pengajaran komponen sastera Bahasa Melayu. GEMA Online Journal of Language Studies, 11 (3): 163-177. USM. Pulau Pinang. 